\title{
Microbial residues as indicator for inorganic carbon transition to organic carbon in coastal saline soils
}

\author{
Pengshuai Shao ${ }^{1}$, Tian $\mathrm{Li}^{1}$, Hongjun Yang${ }^{1}$, and Jingkuan Sun ${ }^{1}$ \\ ${ }^{1}$ Binzhou University
}

September 21, 2020

\begin{abstract}
Although autotrophic or chemotrophic microorganisms can assimilate $\mathrm{CO} 2$ or carbonate, it is still unclear how microorganisms convert soil inorganic carbon (SIC) to organic carbon (SOC), owing to the lack of a microbial indicator between SIC and SOC. Herein, we hypothesized that carbonate-rich saline soils are a potential source that contribute to the SOC pool through the transformation of microbial necromass. SIC levels linearly decreased with an increase in salinity, while SOC and microbial residues exponentially declined. A structural equation model verified the causality of SIC-microbial residues-SOC, suggesting that microbial residues can serve as an indicator of SIC transition to SOC. This study highlights the regulation of microbial necromass in SIC cycling, thus enhancing the application of SIC for C biogeochemical cycles and enriching organic C reservoirs in global saline or dry lands.
\end{abstract}
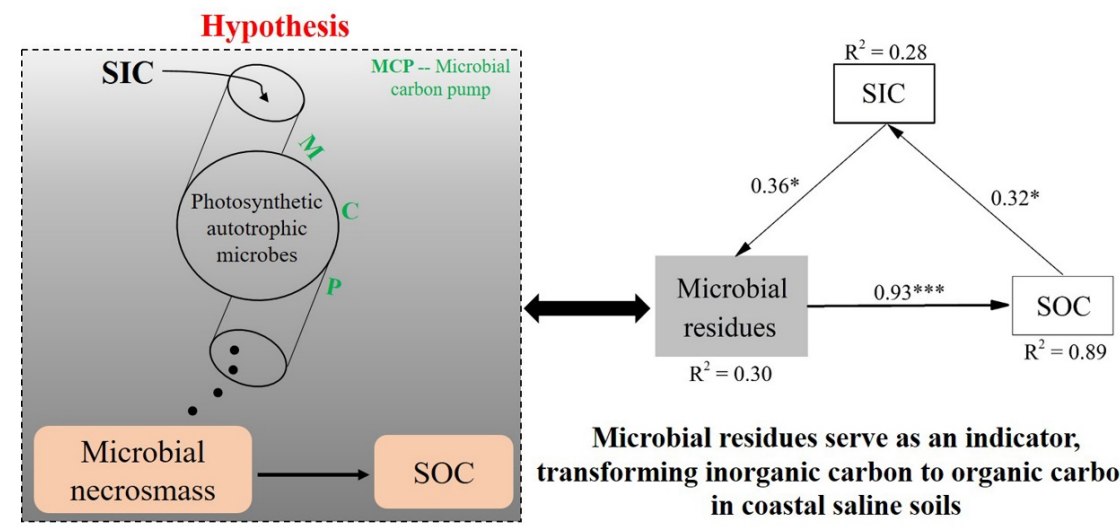

Microbial residues serve as an indicator, transforming inorganic carbon to organic carbon in coastal saline soils

\section{Introduction}

Soil inorganic carbon (SIC), usually as a "missing C sink", accounts for $60-80 \%$ soil C stocks, and essentially influences soil C cycles in saline or dry lands (Mi et al., 2008; An et al., 2019). SIC can be converted to soil organic carbon (SOC), providing organic C source to soil organisms (Groshans et al., 2018). Although plant assimilated inorganic $\mathrm{C}$ is the major SOC source that atmospheric and soil-released $\mathrm{CO}_{2}$ fixed via photosynthesis contributes to the SOC pool through litter and root input (Figure 1, Le Quéré et al., 2018), microorganisms potentially contribute to the conversion of SIC to SOC (Miltner et al., 2004; Liu et al., 2020b). Thus, it is important to speculate the potential mechanisms in the microbially driven SIC-to-SOC transition, thus facilitating soil $\mathrm{C}$ efflux and improving soil fertility in resource-limited saline lands. 
Most microbes use organic matter as energy for reproduction and growth, contributing to the SOC pool through microbial cell residues (Kögel-Knabner, 2017; Ni et al., 2020). However, certain microbes, e.g., photosynthetic bacteria, potentially use SIC (mainly carbonate) as $\mathrm{C}$ source to synthesize cell (Zamanian et al., 2016; Moore et al., 2020). ${ }^{13} \mathrm{CO}_{2}$ incubation experiments have reported that soil autotrophic microorganisms can utilize inorganic C to synthesize microbial biomass (Perez and Matin, 1982; Miltner et al., 2004). Although living microbial biomass constitute only 2-4\% of SOC (Dalal, 1998), rapid, iterative microbial cell growth and death generate sizable microbial necromass entombing in soils, accounting for $>50 \%$ SOM (Kallenbach et al., 2016; Liang et al., 2019). Furthermore, Liang et al. (2017) proposed the concept of a microbial carbon pump (MCP), providing novel mechanistic insights into SOM formation involved in microbial anabolism. Such knowledge and the MCP concept would help predict microorganisms converting SIC to SOC via microbial necromass (Fig. 1).

A systematic field survey was performed to explore the shift in soil $\mathrm{C}$ components (i.e., SIC, SOC, and microbial residues) along a natural salinity gradient. Microbial residue mediation in soil $\mathrm{C}$ transformation was evaluated using biomarkers including amino sugars. We aimed to examine whether the trends in soil C components were consistent from low to high salinity determine the mechanism underlying SIC - microbial residues-SOC.

\section{Materials and methods}

In August 2017, we evaluated 94 sites of saline land in Yellow River Delta (37 $\left.33^{\circ}-38 \mathrm{o} 09^{\prime} \mathrm{N}, 118 \mathrm{o} 35^{\prime}-119 \mathrm{o} 13^{\prime} \mathrm{E}\right)$, China, with 0.50-19.24salinity (Fig. S1), and pH 7.04-8.08 (Fig. S2). Vegetation types primarily included crops (maize, cotton etc.), Phragmites ,Tamarix chinensis, Suaeda salsa, and mudflat.

Five soil cores were randomly collected at each site, pooled, and homogenized into a representative soil sample. Soil $\mathrm{pH}_{(1: 2.5 \mathrm{w} / \mathrm{v})}$ was determined using a $\mathrm{pH}$ meter; total soluble salinity concentration measured by gravimetric method with water ecxtraction (Chi et al., 2019). Carbonate was determined by Acid-base titration, representing SIC (Fu et al., 2020); SOC was analyzed on a Vario MACRO Cube (Elementar, Langenselbold, Germany) after removing SIC with hydrochloric acid. Amino sugars and microbial residues were analyzed using previously reported methods (Zhang and Amelung, 1996; Engelking et al., 2007).

Generalized linear regression models were developed to assess associations among SIC, SOC, and microbial residues (R software). Structural equation modeling (SEM) was performed to trace causality among SIC, microbial residues, and SOC via root-mean-square error of approximation (AMOS software).

\section{Results and discussion}

Along the natural salinity gradient, the SIC was higher at low salinity, $<6$ suggesting that salinity stress influences SIC cycling (Wang et al., 2019). SIC has two potential determinants: (1) uptake and deposition of atmospheric $\mathrm{CO}_{2}$ by base cation (Xie et al., 2009; Raheb et al., 2017), and (2) re-distribution of respired $\mathrm{CO}_{2}$ among microorganisms and roots (Huber et al., 2019). pH markedly influences the magnitude of SIC, soil acidity at low $\mathrm{pH}$ results in SIC loss, and soil alkalinity at high $\mathrm{pH}$ increases atmospheric and soil $\mathrm{CO}_{2}$ absorption of base cations (Liu et al., 2020a; Raza et al., 2020). Slight pH alterations under different saline conditions indicate that SIC alterations are not attributed to regional atmospheric $\mathrm{CO}_{2}$ deposition (Fig. S2). Furthermore, SOM accumulation due to improved plant communities may increase microbial and root respired $\mathrm{CO}_{2}$, retaining SIC via base cation absorption (Lal and Kimble, 2000). Highly photosynthetic crops andPhragmites in low-salinity soil results in higher SIC and SOC than with low-photosynthetic Tamarix chinensis and Suaeda salsa in high-salinity soil (Xia et al., 2019; Fig. S3, Fig. S4). Thus, SIC is increased through changes in organic matter decomposition, further verified through the direct effect of SOC on SIC (Fig. 2c).

Low-salinity soil contains more SOC, displaying a substantial decline at high salinity of $>6$ pointed that plantand microbially-induced C drive SOC storage via litter decomposition and OM transformation (Schmidt et al., 2011; Ding et al., 2019). Plants displaying high-to-low photosynthetic C fixation and the consistent trend between microbial residues and SOC indicate that plant and microbial residues increase SOC storage 
with increasing salinity (Fig. 2a). However, it is still unclear whether other soil C components linking inorganic or organic biogeochemical processes as potential determinants of SOC accumulation, e.g., SIC (primarily carbonate) account for soil $\mathrm{C}$ in approximately $70 \%$ of these regions. We assume that SIC not only provides $\mathrm{C}$ source to autotrophic microorganisms (e.g., cyanobacteria) (Moore et al., 2020), but also serves as a "reserving SOM source" via bio-transformation (Miltner et al., 2004). Significantly linear associations among microbial residues, SOC, and SIC indicate that SIC is a potential determinant of SOC components (Fig. 2b). Furthermore, SEM helped determine the causality and underlying mechanism of SIC-microbial residues-SOC (Fig. 2c), suggesting microbial residues as an indicator for SIC transition to SOC, and verifying our hypothesis.

Despite regulation of terrestrial $\mathrm{C}$ cycles through two microbial metabolic processes, i.e., atmospheric and soil $\mathrm{C}$ release through microbial catabolism and respiratory $\mathrm{CO}_{2}$ fixation into carbonate via base cation absorption (Zhao et al., 2020), microbial anabolism-derived C contributes to the SOC pool (Liang et al., 2017). To better understand soil C cycling, this study describes microbial SIC-SOC conversion, which is important to understand the role of SIC in C cycling in terrestrial ecosystems. SIC generally serves as a potential $\mathrm{C}$ sink and limited information is available regarding its effect on terrestrial C-energy process because of its long-term persistence, high stability, and limited bio-availability (few biomes use SIC as resources) (Zamanian et al., 2018; Liu et al., 2020b). We report the contribution of SIC to SOC stocks, indicating that SIC provides inorganic C-source for other soil biomes after conversion from autotrophic microorganisms. We could not determine the relevant microbial communities or determine the magnitude of the SIC-to-SOC transition. Future studies need to investigate the association between genomic and metabolomic factors in vitro and in situ, especially on the molecular and metabolic process involved in the microbial SIC metabolism and assimilation and the mechanisms followed by specific microbial species, using ${ }^{13} \mathrm{C}$-labeled $\mathrm{CO}_{2}$ or carbonate. Moreover, understanding the role of microbial necromass in SIC transition would enhance SIC applications for C biogeochemical cycles in global saline and dry lands, accounting for the provision of "missing C" to enrich the organic C reservoir through interactions among SIC-microbial metabolites-SOC.

\section{Acknowledgements}

This work was supported by the National Natural Science Foundation of China (41971119, 41871089), the Natural Science Foundation of Shandong Province (ZR2019MD024), the Youth Innovation and Technology Foundation of Shandong Higher Education Institutions (2019KJD010), and the Doctoral Research Start-up Fee of Binzhou University (2019Y18).

\section{Figure legends}

Fig. 1 Conceptual diagram describing biologically driven soil organic (SOC) and inorganic carbon (SIC) cycling. SOC sources from plant litter and root exudates and SIC sources from respired $\mathrm{CO}_{2}$ among microorganisms and roots are highlighted (left diagram); and we hypothesize that microbial necromass play a role in SIC-to-SOC transition in accordance with the microbial carbon pump theory (right diagram).

Fig. 2 C components (i.e., soil inorganic carbon [SIC], soil organic carbon [SOC], and microbial residues) of coastal saline soils $(\mathrm{n}=94)$ in Yellow River Delta. (a ) The shifts in SIC, SOC, and microbial residue levels along a natural salinity gradient; (b ) associations among SOC, microbial residues, and SIC; (c ) structural equation modeling examining the underlying causal relationships among SIC, microbial residues, and SOC.

\section{References}

An, H., Li, Q., Yan, X., Wu, X., Liu, R., Fang, Y., 2019. Desertification control on soil inorganic and organic carbon accumulation in the topsoil of desert grassland in Ningxia, northwest China. Ecological Engineering 127, 348-355.

Chi, Y., Sun, J., Liu, W., Wang, J., Zhao, M., 2019. Mapping coastal wetland soil salinity in different seasons using an improved comprehensive land surface factor system. Ecological Indicators 107, 105517. 
Dalal, R., 1998. Soil microbial biomass-what do the numbers really mean? Australian Journal of Experimental Agriculture 38, 649-665.

Ding, X., Zhang, B., Filley, T.R., Tian, C., Zhang, X., He, H., 2019. Changes of microbial residues after wetland cultivation and restoration. Biology and Fertility of Soils 55, 405-409.

Engelking, B., Flessa, H., Joergensen, R.G., 2007. Shifts in amino sugar and ergosterol contents after addition of sucrose and cellulose to soil. Soil Biology and Biochemistry 39, 2111-2118.

Fu, H., Jian, X., Zhang, W., Shang, F., 2020. A comparative study of methods for determining carbonate content in marine and terrestrial sediments. Marine and Petroleum Geology, 104337.

Groshans, G.R., Mikhailova, E., Post, C., Schlautman, M., 2018. Accounting for soil inorganic carbon in the ecosystem services framework for United Nations sustainable development goals. Geoderma 324, 37-46.

Huber, D.P., Lohse, K.A., Commendador, A., Joy, S., Aho, K., Finney, B., Germino, M.J., 2019. Vegetation and precipitation shifts interact to alter organic and inorganic carbon storage in cold desert soils. Ecosphere $10, \mathrm{e} 02655$.

Kallenbach, C.M., Frey, S.D., Grandy, A.S., 2016. Direct evidence for microbial-derived soil organic matter formation and its ecophysiological controls. Nature Communications 7, 13630.

Kogel-Knabner, I., 2017. The macromolecular organic composition of plant and microbial residues as inputs to soil organic matter: fourteen years on. Soil Biology and Biochemistry 105, A3-A8.

Lal, R., Kimble, J., 2000. Pedogenic carbonates and the global carbon cycle. Global climate change and pedogenic carbonates, 1-14. CRC Press, Boca Raton, USA.

Le Quere, C., Andrew, R.M., Friedlingstein, P., Sitch, S., Hauck, J., Pongratz, J., Pickers, P.A., Korsbakken, J.I., Peters, G.P., Canadell, J.G., 2018. Global carbon budget 2018. Earth System Science Data 10, 21412194.

Liang, C., Amelung, W., Lehmann, J., Kastner, M., 2019. Quantitative assessment of microbial necromass contribution to soil organic matter. Global Change Biology 25, 3578-3590.

Liang, C., Schimel, J.P., Jastrow, J.D., 2017. The importance of anabolism in microbial control over soil carbon storage. Nature Microbiology 2, 1-6.

Liu, S., Zhou, L., Li, H., Zhao, X., Yang, Y., Zhu, Y., Hu, H., Chen, L., Zhang, P., Shen, H., 2020a. Shrub encroachment decreases soil inorganic carbon stocks in Mongolian grasslands. Journal of Ecology 108, 678-686.

Liu, Z., Sun, Y., Zhang, Y., Qin, S., Sun, Y., Mao, H., Miao, L., 2020b. Desert soil sequesters atmospheric $\mathrm{CO}_{2}$ by microbial mineral formation. Geoderma 361, 114104.

Mi, N., Wang, S., Liu, J., Yu, G., Zhang, W., Jobbagy, E., 2008. Soil inorganic carbon storage pattern in China. Global Change Biology 14, 2380-2387.

Miltner, A., Richnow, H.-H., Kopinke, F.-D., Kastner, M., 2004. Assimilation of $\mathrm{CO}_{2}$ by soil microorganisms and transformation into soil organic matter. Organic Geochemistry 35, 1015-1024.

Moore, K.A., Altus, S., Tay, J.W., Meehl, J.B., Johnson, E.B., Bortz, D.M., Cameron, J.C., 2020. Mechanical regulation of photosynthesis in cyanobacteria. Nature Microbiology 5, 757-767.

Ni, X., Liao, S., Tan, S., Wang, D., Peng, Y., Yue, K., Wu, F., Yang, Y., 2020. A quantitative assessment of amino sugars in soil profiles. Soil Biology and Biochemistry 143, 107762.

Perez, R.C., Matin, A., 1982. Carbon dioxide assimilation by Thiobacillus novellus under nutrient-limited mixotrophic conditions. Journal of Bacteriology 150, 46-51. 
Raza, S., Miao, N., Wang, P., Ju, X., Chen, Z., Zhou, J., Kuzyakov, Y., 2020. Dramatic loss of inorganic carbon by nitrogen-induced soil acidification in Chinese croplands. Global Change Biology 26, 3738-3751.

Raheb, A., Heidari, A., Mahmoodi, S., 2017. Organic and inorganic carbon storage in soils along an arid to dry sub-humid climosequence in northwest of Iran. Catena 153, 66-74.

Schmidt, M.W.I., Torn, M.S., Abiven, S., Dittmar, T., Guggenberger, G., Janssens, I.A., Kleber, M., KoegelKnabner, I., Lehmann, J., Manning, D.A.C., Nannipieri, P., Rasse, D.P., Weiner, S., Trumbore, S.E., 2011. Persistence of soil organic matter as an ecosystem property. Nature 478, 49-56.

Wang, X., Jiang, Z., Li, Y., Kong, F., Xi, M., 2019. Inorganic carbon sequestration and its mechanism of coastal saline-alkali wetlands in Jiaozhou Bay, China. Geoderma 351, 221-234.

Xia, J., Ren, J., Zhang, S., Wang, Y., Fang, Y., 2019. Forest and grass composite patterns improve the soil quality in the coastal saline-alkali land of the Yellow River Delta, China. Geoderma 349, 25-35.

Xie, J., Li, Y., Zhai, C., Li, C., Lan, Z., 2009. $\mathrm{CO}_{2}$ absorption by alkaline soils and its implication to the global carbon cycle. Environmental Geology 56, 953-961.

Zamanian, K., Pustovoytov, K., Kuzyakov, Y., 2016. Pedogenic carbonates: Forms and formation processes. Earth-Science Reviews 157, 1-17.

Zamanian, K., Zarebanadkouki, M., Kuzyakov, Y., 2018. Nitrogen fertilization raises $\mathrm{CO}_{2}$ efflux from inorganic carbon: A global assessment. Global Change Biology 24, 2810-2817.

Zhang, X., Amelung, W., 1996. Gas chromatographic determination of muramic acid, glucosamine, mannosamine, and galactosamine in soils. Soil Biology and Biochemistry 28, 1201-1206.

Zhao, X., Zhao, C., Stahr, K., Kuzyakov, Y., Wei, X., 2020. The effect of microorganisms on soil carbonate recrystallization and abiotic $\mathrm{CO}_{2}$ uptake of soil. Catena 192, 104592.

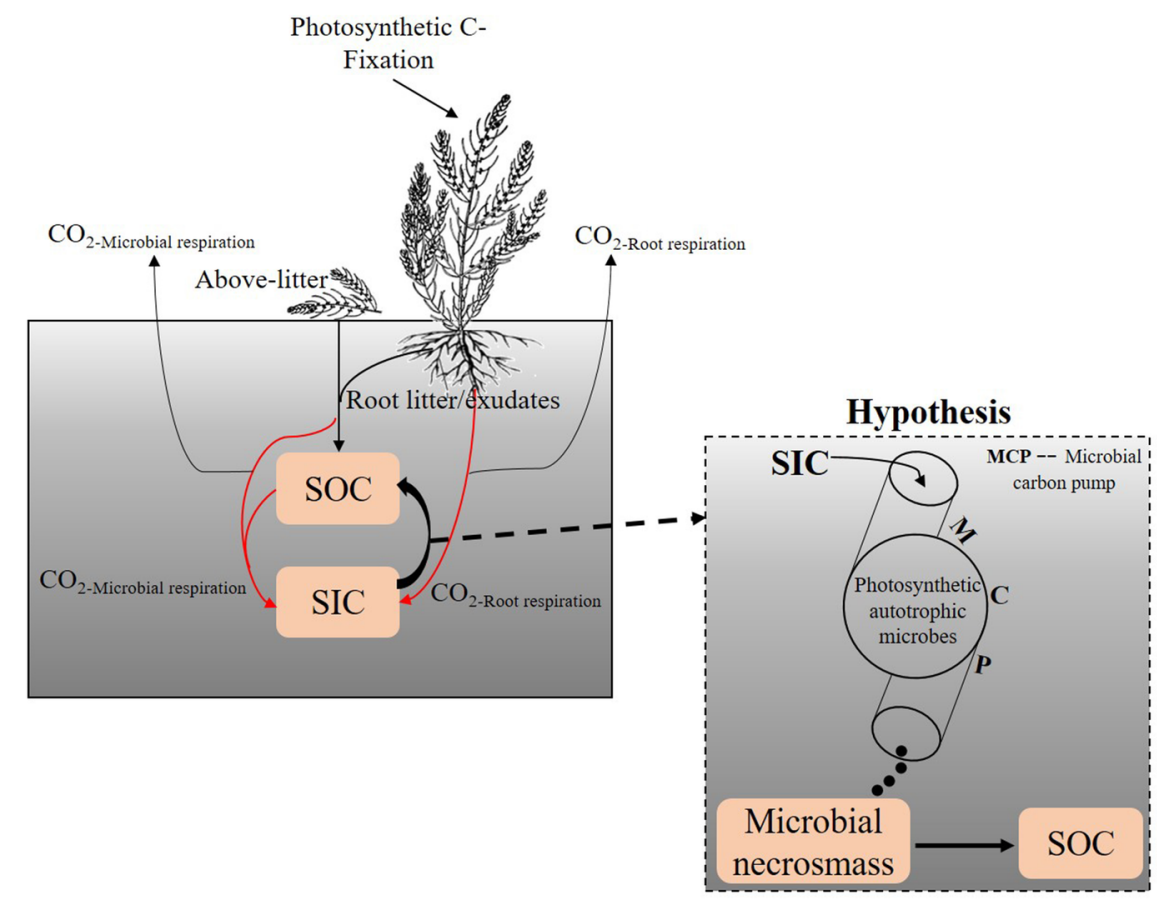



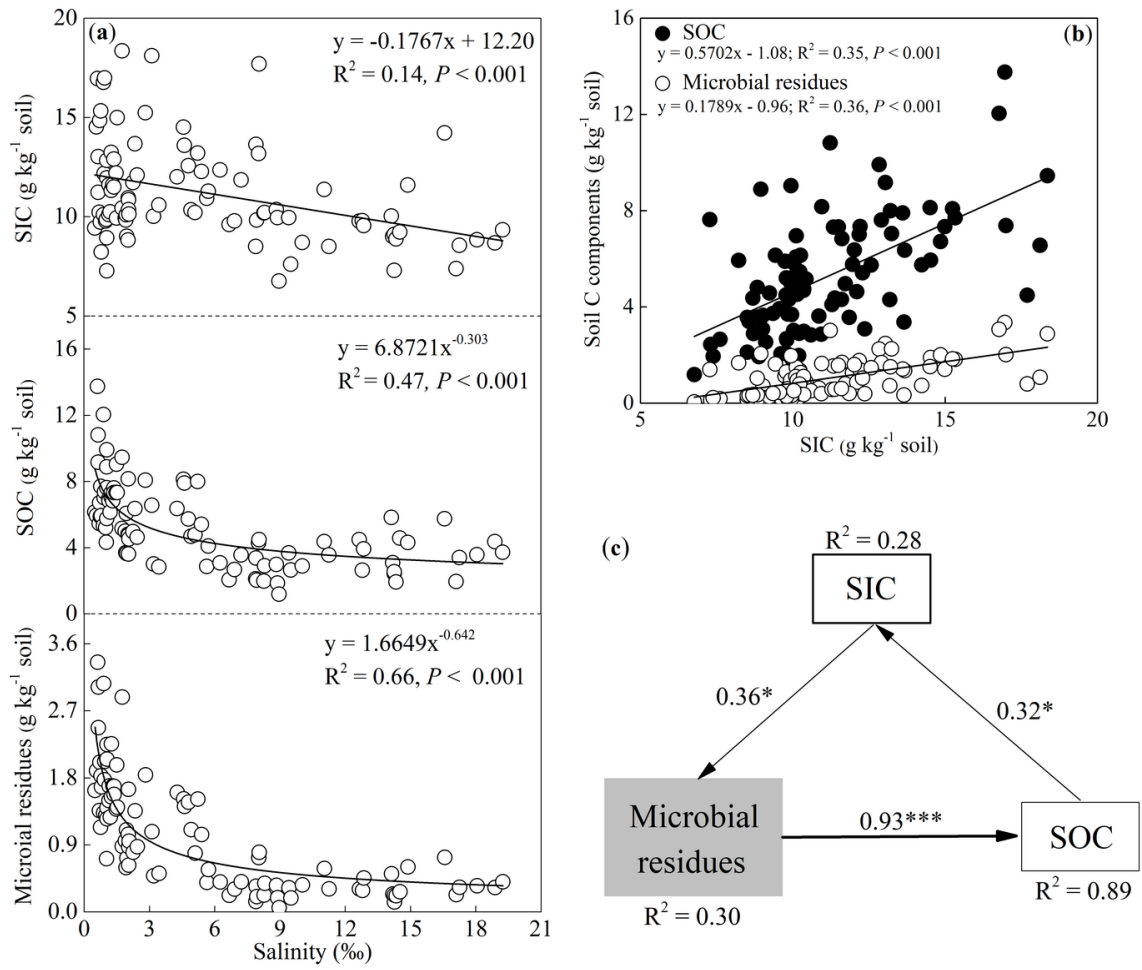